\title{
The use of open window thoracostomy in the management of post-pneumonectomy pleural empyema after gun-shot
}

\author{
Piotr Ostrowski ${ }^{1}$, Maria J. Strandberg Eriksson ${ }^{1}$, Kajetan Kiełbowski $^{1}$, Nikola Ruszel ${ }^{1}$, Jarosław Pieróg ${ }^{2}$, \\ Janusz Wójcik², Bartosz Kubisa² \\ ${ }^{1}$ Student Scientific Society, Pomeranian Medical University, Szczecin, Poland \\ ${ }^{2}$ Department of Thoracic Surgery and Transplantation, Pomeranian Medical University, Szczecin, Poland
}

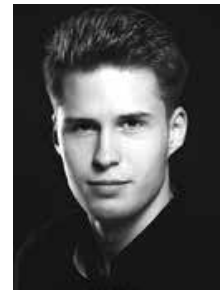

Kardiochir Torakochir Pol 2020; 17 (4): 203-204

Lung gun-shot injury is a life-threatening condition requiring immediate surgical intervention - sometimes even total pneumonectomy. Pneumonectomy is a procedure associated with high mortality and morbidity, and poses a high risk of post-surgical complications, such as rightsided heart failure, ARDS, pneumonia or bronchopleural fistula (BPF) [1]. Among numerous possible complications, postpneumonectomy empyema (PPE) is one of the most serious. We present the case of a patient who has undergone multiple surgical interventions in the past 50 years as a result of PPE and bronchopleural fistula BPF.

In 1970, an 18-year-old male soldier was shot during military training and right-sided pneumonectomy had to be performed (Figures 1, 2). After the appearance of postpneumonectomy empyema, two drainages were applied and empyema was rinsed with chloramine solution. In addition, antibiotic therapy (4 cycles) was applied, with positive outcomes. After a few years the recurrence of PPE was observed due to development of bronchopleural fistula in the bronchial stump. Consequently, it was necessary to perform bronchoplasty. At the time of the recurrence bronchoscopy had confirmed it. Before that, the bronchoscopy did not reveal any fistula. The bronchial stump was sutured using the Klinkenberg technique - continuous non-absorbable suture, double overcast. It was effective until recurrence of the fistula in 2009. As a result, partial thoracoplasty was performed with fenestration (in the form of open window thoracostomy). Four upper right ribs were removed, which resulted in a partially collapsed chest. The initial attempt of fenestration closure was ineffective due to local infection with Pseudomonas. Additionally, foam was appearing from the patient's unclosed anastomosis of the bronchial stump during coughing. On 28 May 2017, the patient was admitted to the Department of Thoracic Surgery and Transplantation with discharge from the wound during coughing. Hospitalization had to be postponed as a result of circulatory insufficiency with cardiac arrhythmia. Due to the patient's deteriorating condition, myoplasties were carried out. The first myoplasty (17 July 2017) was performed after cardiac improvement and involved the use of a dermatomuscular patch $(5 \times 12 \mathrm{~cm})$ made of the pectoralis major muscle. The patch was stitched to the walls of the fistula channel. Povidone-iodine was used for perfusion of the fistula. The second procedure (16 April 2018) included a skin plasty of the thoracostomy entrance to facilitate the necessary weekly aseptic wound cleaning to prevent further contamination. Around 30 small skin patches $(2-4 \mathrm{~mm})$ from the left thigh were harvested for grafting. The entrance of the right-sided thoracostomy was cleaned and the skin patches were applied. The patient's condition has notably improved and currently there are no symptoms of another recurrence. Postpneumonectomy empyema and bronchopleural fistula are rare complications that can develop even years after the initial procedure. The risk factors for these conditions include infections, chronic obstructive pulmonary disease, smoking and another surgical intervention. Furthermore, right-sided pneumonectomy brings more risks for developing BPF due to the differences in blood supply of the lungs and bronchus [2]. Management of chronically infected post-pneumonectomy pleural empyema requires several challenging treat-

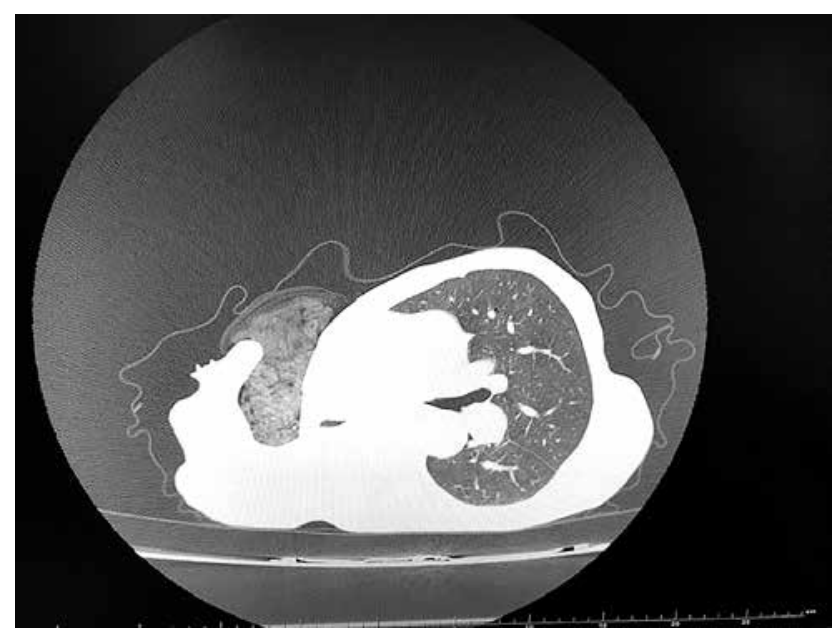

Figure 1. Computed tomography of the patient's chest. Visible gauze dressing inside the pleural cavity (4.04.2017)

Address for correspondence: Piotr Ostrowski, Student Scientific Society of Pomeranian Medical University, Szczecin, Poland,

e-mail: piotr.ostrowski1997@gmail.com

Received: 10.08.2020, accepted: 3.11.2020. 


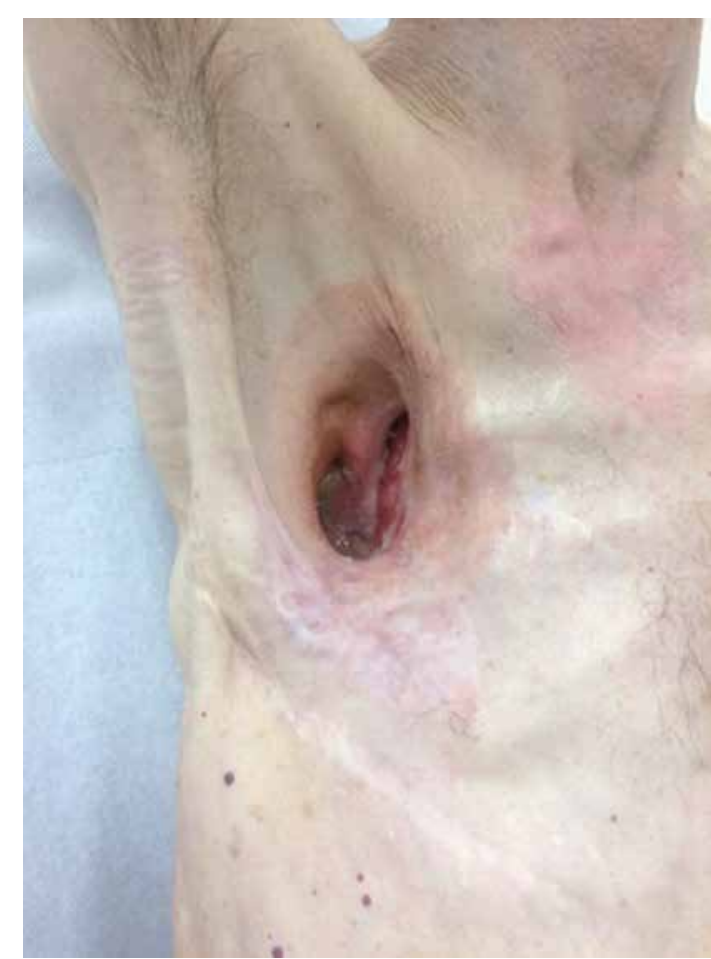

Figure 2. Patient's chest after myoplasty and recovery (29.08.2019)

ment strategies. These include closing the fistula, and eradication of the pleural empyema [3] followed by obliteration of the pleural space.

Firstly, pleural drainages and antibiotics are used to clear the postpneumonectomy space. After that, if the fistula is present, open window thoracostomy is usually performed for debridement [4]. If there is no improvement, partial or total thoracoplasty is performed to obliterate the pleural space. With a smaller resection cavity, the probability of developing empyema is much lower, but removing four upper ribs caused chest deformation. In this case, recurrences were observed, so myoplasty had to be performed, with positive outcomes.

There were three recurrences in total with late BPF. The patient was tall, cachectic and received suboptimal nutri- tion. Moreover, due to the patient's occupation (being an active soldier), he was exposed to various infections during military training which contributed to the recurrences and development of the fistula. Additionally, diabetes might have slowed down wound healing. These recurrences might have developed as a result of long bronchial stumps, since there is a correlation between BPF and stump length [5]. Furthermore, presence of fluid in the postpneumonectomy space might cause recurrences as well [6]. In addition, myoplasty, which provides vascularization for the tissues around the bronchial stump, prevents empyema recurrence [7].

To conclude, treatment of this particular patient required rethinking already known methods as a result of many surgical interventions performed in the past. Finally, after complete eradication of empyema, covering the stump with a muscle flap and obliteration of pleural space, there are no more signs of active empyema and fistula.

\section{Disclosure}

The authors report no conflict of interest.

\section{References}

1. Phillips B, Turco L, Mirzaie M, Fernandez C. Trauma pneumonectomy: a narrative review. Int J Surg 2017; 46: 71-74.

2. Hicham H, Ibrahim I, Rabiou S, Marouane L, Yassine O, Mohamed S. Postpneumonectomy empyema: risk factors, prevention, diagnosis, and management. Asian Cardiovasc Thorac Ann 2020; 28: 89-96.

3. Andreetti C, Menna C, D’Andrilli A, Ibrahim M, Maurizi G, Poggi C, Rendina EA, Venuta F, Santini M, Fiorelli A. Multimodal treatment for post-pneumonectomy bronchopleural fistula associated with empyema. Ann Thorac Surg 2018; 106: 337-339.

4. Bribriesco A, Patterson GA. Management of postpneumonectomy bronchopleural fistula: from thoracoplasty to transsternal closure. Thorac Surg Clin 2018; 28: 323-335.

5. de la Riviere AB, Defauw JJ, Knaepen PJ, van Swieten HA, Vanderschueren RC, van den Bosch JM. Transsternal closure of bronchopleural fistula after pneumonectomy. Ann Thorac Surg 1997; 64: 954-7.

6. Arrivé L, Tasu JP, Kitzis M, Lesęche G, Najmark D, Duchatelle JP, Nahum H. Open window thoracostomy, myoplasty, and epiploplasty for treatment of postpneumonectomy empyema: CT evaluation. Radiology 1994; 192: 177-181.

7. Schreiner W, Dudek W, Sirbu H. Combined Clagett procedure, negative pressure therapy, and thoracomyoplasty for treatment of late-onset postpneumonectomy empyema necessitatis. Kardiochir Torakochir Pol 2015; 12: 259-261. 